\title{
Situated Professional Communication: A Rhetorical Approach
}

\author{
Corey Owen and Debora Rolfes \\ Ron and Jane Graham School of Professional Development, College of Engineering \\ University of Saskatchewan \\ corey.owen@usask.ca, debora.rolfes@usask.ca
}

\begin{abstract}
Using the insights of Situated Learning Theory, Genre Theory, Learning Transfer Theory, and Activity Theory, the authors of this paper reflect on the challenges of offering a professional communication programme to students from different colleges and different disciplines within each college, and examine how grounding their programme within the tradition of rhetoric, and creating a community of practice in which students are apprenticed as rhetoricians, is a potential solution to these difficulties.
\end{abstract}

Keywords: Professional Communication, Rhetoric, Learning Theory, Situated Learning, Learning Transfer Theory

\section{INTRODUCTION}

One of the greatest and most widely acknowledged problems with teaching professional communication is the difficulty of designing courses that adequately prepare students for the many different types of communication they will be expected to engage in regularly when they enter the professional workplace. As Aviva Freedman and Christine Adam found in their study of the teaching of communication in professional programmes, "Even in courses where the instructor is directly simulating a workplace task through a factually based case study, the nature of writing is fundamentally different because of the radical differences between the two rhetorical contexts" [1]. This challenge is compounded in programs like the one offered by the Graham School of Professional Development in the University of Saskatchewan's College of Engineering, in which faculty teach professional communication not only to all of the disciplines in the College of Engineering, but also those in the College of Agriculture as well. Using scholarship by theorists such as Carolyn Miller, Jean Lave, Etienne Wenger, Aviva Freedman, Christine Adam, Natasha Artemeva, and Doug Brent, that unifies the diverse, yet closely related critical frameworks provided by Activity Theory, Genre Theory, Situated Learning Theory, and Learning Transfer Theory, the authors of this paper reflect on how the Graham School is able to contribute to the professionalization of our students through the creation of a united community of practice. In particular, we explore how apprenticing our students as practitioners of rhetoric, a discipline that offers a reflective discourse for assessing and engaging in professional communication, creates identities as individuals within a cohesive group that prepares them to adapt to their specific professional community after graduation, and gives them a critical tool for designing their own persuasive messages as well as assessing the persuasive messages of others. This community of practice is effectively reinforced through our community of scholars within the School, all of whom are actively and diversely engaged in the study of the rhetoric, as well as our extracurricular events, such as our public speaking competition, and, perhaps most of all, through our Professional Communication Option (PCO), a programme that requires students to take six half-credit courses in addition to their regular engineering curriculum.

\section{RESULTS AND DISCUSSION}

\subsection{The community of rhetoric practitioners}

Our professional communication programme is delivered by a group of scholars who collectively form a community of practice. According to Etienne Wenger, a common practice unites three dimensions of such a community: joint enterprise, mutual engagement, and shared repertoire [2]. Our obvious joint enterprise is to teach our courses as effectively as possible, given our institutional constraints; however, we are also committed to the study of rhetoric. Thus, we experience mutual engagement through both our collective contributions to the content of Rhetorical Communication 300, our introductory course, as well as through our regular research meetings, in which we discuss the development of our conference papers and articles. Our shared repertoire comes not only from our study and teaching of a discipline known as new rhetorics, a revision of classical rhetoric initiated by such theorists as Kenneth Burke, Wayne Booth, and Lloyd Bitzer, but also through the experience that many of us share of being founding members of an academic programme at the University of Saskatchewan-four out of six of our permanent faculty members saw the birth of the Rhetorical Communication programme, and the other two came along shortly after. Thus, our professional communication programme is built on a community of mutually-engaged scholars, all of whom are committed to teaching and researching professional communication from a rhetorical perspective.

The discipline of Rhetoric is a useful one for teaching professional communication, because it provides students with a paradigm and corresponding discourse 
that enables them to assess the professionalism of others and cultivate their own professionalism. Joining the community of rhetoricians at the School of Professional Development not only facilitates the transfer of professional communication skills, but it also provides them with theoretical tools that will enable them to become reflective practitioners, that is, professionals who are able to reflect carefully on their own professionalism. ${ }^{1}$

\subsection{Developing identity as a rhetorician}

According to Etienne Wenger's theory of social learning, participation ultimately confers identity: "Participation here refers not just to local events of engagement in certain activities with people, but to a more encompassing process of being active participants in the practices of social communities and constructing identities in relation to these communities" [2]. The central practice of our community consists of teaching Rhetorical Communication (RCM) 300, in which we invite students to join our community of practice, at least in a peripheral manner, by introducing them to rhetorical terminology that enables them to reflect on their own communication, as well as that of others. ${ }^{2}$ Terms such as ethos, pathos, logos, rhetorical exigence, rhetorical audience, and constraints, as well as footing and face, provide students with a toolkit for becoming more effective communicators, and they also encourage students to identify themselves as members of a group of communication practitioners, of rhetoricians, who, no matter what their profession, are united by their common purpose - to become effective professionals by developing and practicing the skills of effective rhetorical persuasion.

RCM 300 culminates in nearly three weeks of speech rounds, during which the students' understanding of the application of the rhetorical theory they learn is continuously developed and reinforced. During these rounds, the students use the theory both to compose their own persuasive speech and to reflect on the success of others. In essence, they assess the success of others in forming a professional identity - they take the role of the community into which they will shortly be entering as neophyte professionals and assess the skills and strategies that their peers are cultivating.

As Doug Brent observes, Activity Theory, a social theory that investigates how individuals produce social action, posits that different motivations can make the "similarities between ... activities ... superficial at best"; thus, while it can "give us a richer way of describing rhetorical exigencies as arising from activities

\footnotetext{
${ }^{1}$ On the concept of the reflective practitioner, see Donald Schön [3].

${ }^{2}$ On peripheral participation, see Lave and Wenger [4]. While most students will probably never reach the full participation of the faculty members, since they are ultimately pursuing employment in different professions, many still become rhetorical scholars by practising the study of rhetoric beyond their university studies.
}

and activity systems, and from the social motives behind them[,] it only deepens the problem of transfer" [5]. Motivation can be a key determinant in the success of transferring skills from one context to another. For instance, in RCM 300, students presumably complete the various assignments such as the formal report and the extemporaneous speech with the primary goal of achieving a decent grade. Their potential for transferring the skills they learn in the class could be limited by their desire simply to learn only what's necessary to succeed in the particular situation of the classroom.

In our programme, however, we attempt to further facilitate learning transfer by holding such events as the Graham School Public Speaking Competition. The students who enter the competition are now eligible for a substantial cash prize, but such a motivating factor was introduced only recently, and has not increased the number of competitors. Traditionally, students who have completed RCM 300 have competed in order to perfect their skills, and current RCM 300 students have attended to better understand the extemporaneous speaking assignment they would soon be completing.

In essence, the public speaking competition reinforces the community of rhetoric practitioners by further conferring the identity of rhetorician upon the students. The audience members attend the competition equipped with the rhetorical terminology that we teach them in RCM 300, and they use that terminology to evaluate the speeches. In the following class, we discuss the merits and difficulties of each speech using such concepts as ethos, pathos, and logos. The motivation for attending or competing in the competition goes beyond the desire to achieve a good mark in the class, since doing so has little, if any, direct academic benefit. Instead, such an event reinforces identity through group participation in a rhetorical extracurricular activity, and this identity can transcend the traditional rivalry between the rival colleges of Agriculture and Engineering.

\subsection{Full participation and mentorship}

While the rhetorical theory, extemporaneous speech, and public speaking competition all represent progressive stages in our attempt to enculturate our students into our community of rhetoric practitioners, the Professional Communication Option (PCO) ultimately completes this process of identity formation, and ensures that students who complete the programme will carry their identity as rhetoricians beyond their university experience. Students take six half-credit courses, which may include rhetorical theory, public speaking, interpersonal communication, document design and editing, leadership, communication ethics, language structure, rhetorical composition, negotiation, as well as a practicum involving peer mentorship. All of these courses are informed by a common body of theory, and in each course, the students' understanding of the theory is 
enhanced through their opportunity to apply it in diverse communication situations. The various contexts in which they apply the theory increase the likelihood that the students will be able to successfully apply the theory in any professional environment. While taking our 400 level classes, students gradually evolve from being newcomers to becoming old-timers, to use the terminology of Jean Lave and Etienne Wenger [4], and, as they become more experienced, they have the opportunity to become involved in mentoring RCM 300 students who are preparing to write reports and deliver speeches.

\section{CONCLUSIONS}

While the professional communication programme in the College of Engineering at the University of Saskatchewan is young and, naturally, a work in progress, it attempts to enculturate students into a community of rhetoric practitioners. Our goal of enculturating students into our community of practice is to help improve their ability to adapt to whatever professional community of practice they find themselves in throughout their careers. ${ }^{3}$ Such enculturation occurs not only through the common theoretical approach we teach our students in RCM 300, but also through our community-building events, such as our public speaking competition, our Professional Communication Option, and, of course, our own practice as a community of rhetorical scholars, all of whom are engaged in the study and teaching of the discipline of rhetoric.

\section{Acknowledgements}

The authors would like to their colleagues at the Graham School for their contributions to and reflections on the curriculum of the School's programme.

\section{References}

[1] Aviva Freedman and Christine Adam, "Learning to write professionally: 'Situated Learning' and the transition from university to professional discourse," Journal of Business and Technical Communication, vol. 10, no. 4, pp. 395-427, 1996.

[2] Etienne Wenger, Communities of Practice: Learning, Meaning, and Identity, Cambridge: Cambridge UP, 1998, 318 pp. \{ISBN: 978-0-521-66363-2\}

[3] Donald Schön, The Reflective Practitioner: How Professionals Think in Action, London: Temple Smith, 1983, 374 pp. \{ISBN: 0-465-06878-2\}

\footnotetext{
${ }^{3}$ As Brent notes, "many studies in learning transfer emphasize long-term pedagogical experiences that are aimed at creating a deep well of expertise and enculturating students into the long-standing mental habits, or dispositions, that will enable them to use that expertise in new situations. This kind of enculturation depends on repeated and consistent exposure" [4].
}

[4] Jean Lave and Etienne Wenger, Situated Learning. Legitimate Peripheral Participation, Cambridge: Cambridge UP, 1991, 138 pp. \{ISBN: 978-0-521-42374-8\}

[5] Doug Brent, "Transfer transformation, and rhetorical knowledge: insights from transfer theory," Journal of Business and Technical Communication, vol. 25, no. 4, pp. 396-420, 2011. 